\title{
The influence of climatic conditions on the thermal state of frame partitions insulated with loose fiber materials
}

\author{
Piotr Kosiński ${ }^{1, *}$, and Aneta Skoratko ${ }^{1}$ \\ ${ }^{1}$ University of Warmia and Mazury in Olsztyn, Faculty of Geodesy, Geospatial and Civil \\ Engineering, Insititute of Building Engineering, 10-437 Olsztyn, Ul. Heweliusza 10, Poland
}

\begin{abstract}
The paper focus of the influence of the climatic conditions on thermal state and heat transfer of the frame partitions insulated with loose wood wool. While it is well known that building materials change thermal conductivity depending on the operating temperature, the always question is how much it influences on the whole element. The paper presents the laboratory results from the hot box chamber investigation of the frame partition. These results are compared with the simulation results.
\end{abstract}

\section{Introduction}

Fibrous materials are characterized by good thermal properties and their great advantage is the possibility of using them as batt but as loose and bulk materials as well. This means that they can be used to insulate almost each space except for places that are constantly wet, although work is being carried out on the drying capacity of fibrous materials, particularly cellulose fibers [1]. Fibrous materials are characterized also by high porosity, which increases with decreasing their thermal conductivity. This leads to an increase of air permeability, which may result in a counterproductive effect - natural convection in the material that leads to increased heat transfer in insulation. In addition, thermal losses are also inducted by forced convection caused by, for example, windwashing [2]. Particular attention should therefore be paid to the protection of fiber insulation against air filtration.

These features make fibrous materials still the object of research and development of new production technologies and their use in constructions.

\section{Loose fiber insulation materials}

In addition to popular and well-known materials (stone and glass wool), fibrous materials of natural or secondary origin become more and more popular. This is part of the policy of sustainable development. In technical terms, it manifests itself, among others in increased market share of thermal insulation materials in the form of bulk, granulated and loose materials, e.g. loose mineral wool or cellulose granulate. Research on the use of plantderived materials, such as: ramie, flax, hemp, kapok, cotton, kenaf, sisal, bamboo, jute,

*Corresponding author: piotr.kosinski@uwm.edu.pl 
coconut as thermal insulations are conducted [3, 4]. The studies include thermal and mechanical properties of materials. The materials are characterized by high air and vapour permeability, for many materials yet undefined. A lot of research is conducted on the hygrothermal properties of wood fibers and wood wool [5-7]. The construction of fibrous thermal insulation materials, like wood wool is clearly visible under microscopic magnification (Fig. 1a), the spaces between fibers are higher than fiber diameter.

In the laboratory of building physics at the University of Warmia and Mazury in Olsztyn the works on the use of loose fiber materials as thermal insulation are carried out. It has been noticed, that the density impact on hygrothermal properties is the specific feature of fibrous materials. Each material is characterized by the certain density at which the thermal conductivity coefficient reaches the smallest value. With increasing bulk density of the material in the bulk condition, the thermal conductivity decreases, reaches a minimum, and then increases with increasing density. During compaction, convection in the pores is limited, but at high density, conduction between the fibers occurs. Another feature that plays significant role in the hygrothermal behaviour of these materials is the fragmentation of the fibers. The Fig. $1 \mathrm{~b}$ presents the dependence of the thermal conduction coefficient of loose wood wool fibers on their density at the average sample temperature of $+10^{\circ} \mathrm{C}$. The results for 10 measurement series of the tested material are presented. The variety of results was caused by a different degree of fiber fragmentation.

a)

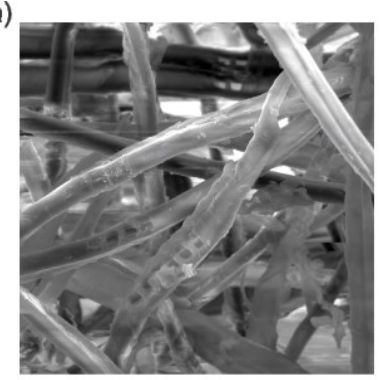

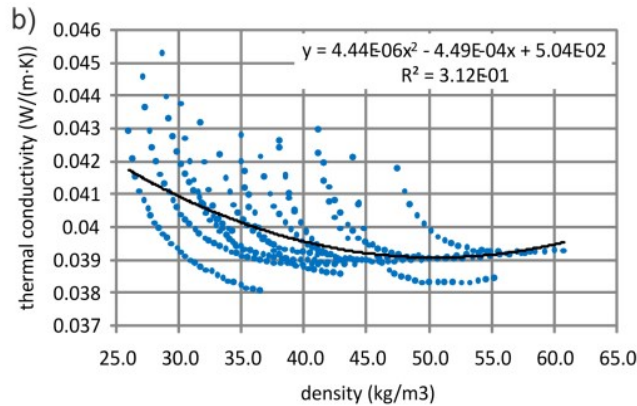

Fig. 1. Loose wood wool, a) electron microscope image of loose wood wool at 754 times magnification, b) a relation of thermal conductivity and density of loose wood wool.

A study of hygrothermal parameters of wood and wood-based products, but gypsum wallboards as well showed linear behaviour for temperatures between $10^{\circ} \mathrm{C}$ and $40^{\circ} \mathrm{C}$ while in the higher temperature range the tendency is not linear $[7,8]$. The general tendency of light materials, especially thermal insulations [9] is to decrease the thermal conductivity with lowering the ambient temperature. It should be noted, that heat conduction through gas is dominant in light insulating materials, and this decreases with the decrease in temperature. Material tests are usually carried out on small specimen with dimensions smaller than building elements. Tests on real scale models can give a response to the thermal state of the actual building elements.

\section{Method}

\subsection{General}

The question about the thermal stability of frame partitions filled with fibrous materials occurs increasingly amongst designers and investors. The research presented in this work is a stage of a larger project on the thermal stability of partitions filled with loose thermal insulation materials. The inspiration for the topic were studies conducted from the 1970- 
80 s, initially in the USA and Canada, on thermal protection of buildings with high thermal capacity of enclosure. The use of thermal mass has been shown to be an effective means of reducing both heating and cooling loads in residential buildings. Research has shown that partitions with low thermal insulation but high thermal capacity, such as, for example, wooden beam walls can protect interior as well as those with high thermal insulation, but low thermal capacity $[10,11]$. Each time a question is if there is a simple correlation between thermal insulation and thermal capacity of different materials in building elements which will result in similar thermal protection properties.

The following type of wood frame wall was tested (from exterior side):

- $20 \mathrm{~mm}$ plywood,

- $250 \mathrm{~mm}$ loose wood wool,

- $12.5 \mathrm{~mm}$ gypsum board.

\subsection{Experimental set-up}

The investigation was carried out twice on the same model of frame partition filled with loose wood wool. The model consisted of a wooden frame made of pine boards $(50 \times 250$ $\mathrm{mm}$ ). External dimensions of the frame $1460 \times 1460 \mathrm{~mm}$. On one side, a $12.5 \mathrm{~mm}$ thick gypsum board was attached to the frame, constituting the inner shell of the model. The frame was filled by hand using mechanically shredded wood wool in a loose state with a bulk density of $45 \mathrm{~kg} / \mathrm{m}^{3}$. Next, a $20 \mathrm{~mm}$ thick plywood was fixed to the wooden frame to form a closed skeleton partition. The model was constructed in a horizontal position. Next, the model was mounted in the inspection frame of the hot box, and in order to avoid thermal bridges and eliminate external influences, the sample was additionally circumferentially insulated with mineral wool.

Next on both surfaces of the model thermocouples were connected. The sensors layout is shown in Fig. 2. On the warm side, a centrally located heat flux meter was mounted, and the entire surface was covered with a protective mat. The final stage was to place the inspection frame in the chamber and run the measurements.

a)

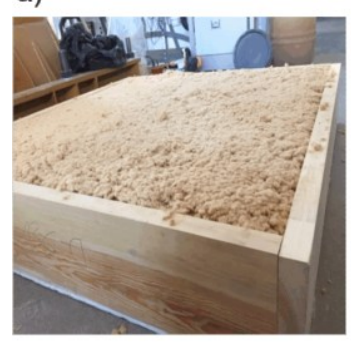

b)

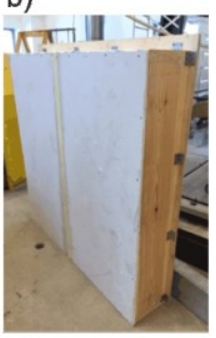

c)

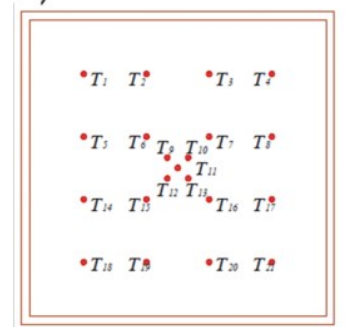

d)

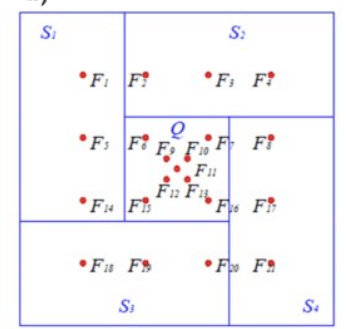

Fig. 2. Hot box investigation, a) model during construction, b) model, c-d) temperature sensors' layout on hot and cold surface of the sample: c) cold side with thermocouples T1-T21, d) hot side with protective plates (S1-S4) on thermocouples F1-F21 and heat flux density meter (Q).

The experiment was divided into two stages. The first one was carried out immediately after assembling the model and lasted two months. Then there was a 4 months breaks and the second stage which lasted 2 months again. During the break period, the sample was stored in a vertical position in laboratory conditions. The second stage therefore started half a year after assembly and storage in a vertical position. By separating the two stages, it was possible to see if any subsidence of fibers in the model could have an impact on the results.

The measurement was based on the recording of temperature values and the heat flux density at 2 -minute intervals. The average values were calculated every 120 minutes. The measuring cycle has been programmed to end when five consecutive intermediate values 
(120 minutes) do not differ from each other by more than $1 \%$. Average temperature values on both sides were used to calculate average temperature of the model. During the test, the humidity and air speed in each part of the chamber were also recorded. In addition, thermal resistance and average heat flux were determined.

\subsection{Material}

The examined model was filled with loose wood wool of density $45 \mathrm{~kg} / \mathrm{m}^{3}$. During filling the model, care was taken to ensure equal distribution and density of insulation. The specific heat of wood wool is about $2100 \mathrm{~J} / \mathrm{kg} \cdot \mathrm{K}$, which is almost 3 times more than insulation made of mineral wool, while the thermal conductivity coefficient of wood wool is slightly higher than mineral wool [12]. Studies on the use of wood wool as thermal insulation indicated similar thermal and moisture properties as mineral wool. There were indications that loose fill wood wool insulation performs slightly better than batt wood wool insulation regarding to moisture conditions [5]. It is worth of notice that wood-based materials, because of their nature and anisotropy (diverse origins, presence of plant fibres, high and irregular porosity, etc.) are very heterogeneous materials.

\subsection{Boundary and initial conditions}

The boundary conditions for individual measurements were different. The temperature range on the cold side: from $-10.0^{\circ} \mathrm{C}$ to $15.0^{\circ} \mathrm{C}$ while on the warm side: from $15.0^{\circ} \mathrm{C}$ to $35.0^{\circ} \mathrm{C}$, with the tolerance $\pm 0.6^{\circ} \mathrm{C}$. An intention was to achieve difference of 20.0 or 25.0 or $30.0^{\circ} \mathrm{C} \pm 0.6^{\circ} \mathrm{C}$ between the sides. A total of 20 temperature pairs were set, however, 3 measurements had to be rejected due to technical problems of the recording device. The work presents 9 results from the first measurement series and 8 from the second (Fig. 3a).
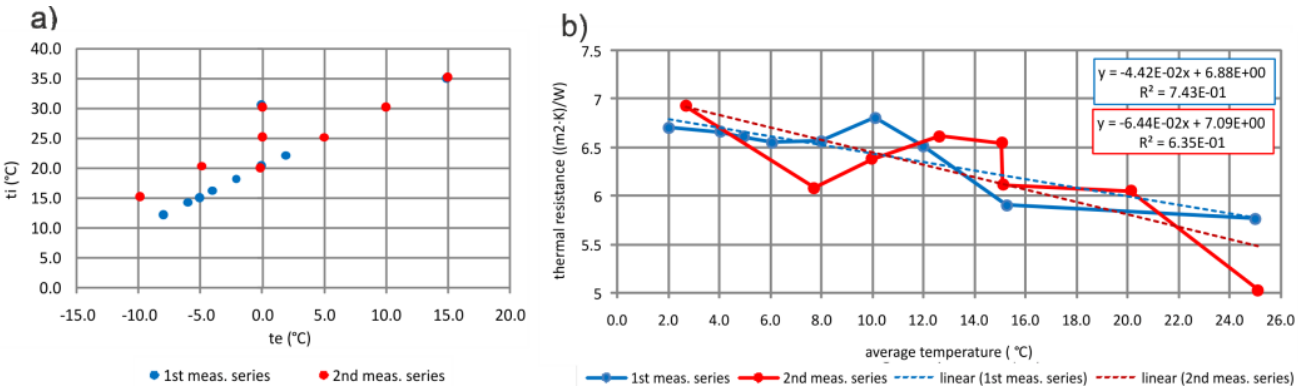

Fig. 3. a) Temperature set for measurements b) results of total thermal resistance

\subsection{Results and discussion}

The stabilization time of the samples was different for measurements and ranged from 36 to 118 hours for the first series and from 32 to 64 hours for the second. The longest stabilization lasted for the first measurements in each study period, what might be explained by the time needed to achieve thermal equilibrium. The length of stabilization should not affect the test results.

Fig. $3 \mathrm{~b}$ shows the results of total thermal resistance of a sample for two measurement series. The results are presented in rising order of average model temperature. In the case of the first measurement series, a constant decrease in thermal resistance is visible along with the increasing average temperature $\left(\mathrm{t}_{\text {mean }}\right)$ from $6.705 \mathrm{~m}^{2} \cdot \mathrm{K} / \mathrm{W}$ for $\mathrm{t}_{\text {mean }}=2.03^{\circ} \mathrm{C}$ to 5.909 $\mathrm{m}^{2} \cdot \mathrm{K} / \mathrm{W}$ for $\mathrm{t}_{\text {mean }}=15.25^{\circ} \mathrm{C}$. Only for the average temperature of $10.12^{\circ} \mathrm{C}$, the obtained 
result deviates from the trend. Linear regression approximates the results with the adjustment $R^{2}=0.743$. In the case of the second measurement series, the thermal resistance decrease is also noticeable with the increasing average temperature from $6.928 \mathrm{~m}^{2} \cdot \mathrm{K} / \mathrm{W}$ for $\mathrm{t}_{\text {mean }}=-9.93^{\circ} \mathrm{C}$ to $5.032 \mathrm{~m}^{2} \cdot \mathrm{K} / \mathrm{W}$ for $\mathrm{t}_{\text {mean }}=20.16^{\circ} \mathrm{C}$, but in this case as many as 3 results differ from the trend. Linear regression approximates the results with the adjustment $\mathrm{R}^{2}=0.635$.

An interesting situation is at an average temperature of around $15.0^{\circ} \mathrm{C}$ where 3 different results were achieved. For the first series of measurements for a temperature pair of $30.62^{\circ} \mathrm{C}$ and $-0.12^{\circ} \mathrm{C}$ a total measured thermal resistance $\left(\mathrm{R}_{\text {tot }}\right)$ of $5.909 \mathrm{~m}^{2} \cdot \mathrm{K} / \mathrm{W}$ was achieved, for the second series of measurements for a temperature pair of $30.22^{\circ} \mathrm{C}$ and $0.00^{\circ} \mathrm{C}$ it was $6.117 \mathrm{~m}^{2} \cdot \mathrm{K} / \mathrm{W}$ while for a temperature pair of $25.17^{\circ} \mathrm{C}$ and $4.97^{\circ} \mathrm{C} \mathrm{R}_{\text {tot }}=$ $6.549 \mathrm{~m}^{2} \cdot \mathrm{K} / \mathrm{W}$. There is also a discrepancy between the results at an average temperature $10.0^{\circ} \mathrm{C}$ where the conditions $20.0^{\circ} \mathrm{C}$ and $0.0^{\circ} \mathrm{C}$ were set in both measurement series.

On the base of results it can be noticed that the model tends to reduce the $\mathrm{R}_{\text {tot }}$ with the $\mathrm{t}_{\text {mean }}$ increase. The linear regression is adjusted in at least $63 \%$. In the case of the second measurement period, the obtained thermal resistance values show larger deviations from the linear waveform than in the first measurement period. This may be related to the compression and deformation of loose wood wool in the sample in time, what may affect the obtained results. The answer may be brought by the planned next series of measurements, which will repeat the temperature pairs.

\section{Simulation}

Thermal simulations were performed using the Control Volume Method in the Delphin 5.8 software in order to compare the laboratory results with steady state heat transfer calculations. The model was constructed on the base of the hot box investigation, including the model dimensions, thickness of the layers and location of measuring probes. Physical data for the simulation, including material properties and boundary conditions: temperature, air speed and relative humidity were adopted on the basis of laboratory measurements. Boundary conditions were also used to calculate surface resistances of model for each pair of temperatures. Physical properties of materials are presented in Table 1.

Table 1. Physical properties of materials used in the simulation

\begin{tabular}{|c|c|c|c|c|}
\hline Material & $\mathrm{d}(\mathrm{m})$ & $\lambda(\mathrm{W} /(\mathrm{m} \cdot \mathrm{K}))$ & $\rho\left(\mathrm{kg} / \mathrm{m}^{3}\right)$ & $\mathrm{Cp}(\mathrm{J} / \mathrm{kgK})$ \\
\hline Gypsum board & 0.0125 & 0.2000 & 850 & 850 \\
\hline Loose wood wool & 0.25 & 0.0392 & 45 & 2100 \\
\hline Plywood & 0.02 & 0.0420 & 150 & 2000 \\
\hline Spruce & $0.06 \times 0.25$ & 0.1298 & 520 & 1120 \\
\hline
\end{tabular}

Fig. 4 presents the results of measured and simulated thermal transmittance sorted by the average temperature of the model. Thermal transmittance values of the laboratory model were calculated on the basis of average values of heat flux and temperature difference. Similarly, in the case of simulation, using the calculated values.

The course of changes is different for measurements and simulations. In the case of both measurement series, the trend is growing along with the temperature increase (angles of linear regression curves: $1.057 \mathrm{E}-03$ and 1.897E-03). In the case of simulations, the increasing trend with the temperature increase is smaller (angles of linear regression: $1.347 \mathrm{E}-05$ and 6.779E-05). It should be noted, that due to the lack, in the moment of simulation, of precise values of thermal conductivity, depending temperature, of the used materials, the simulation model was not sufficient calibrated with laboratory tests. Despite 
this, convergence of simulation and measurement values towards the lower temperature can be observed. Currently, the material properties examination is carried out.

a)

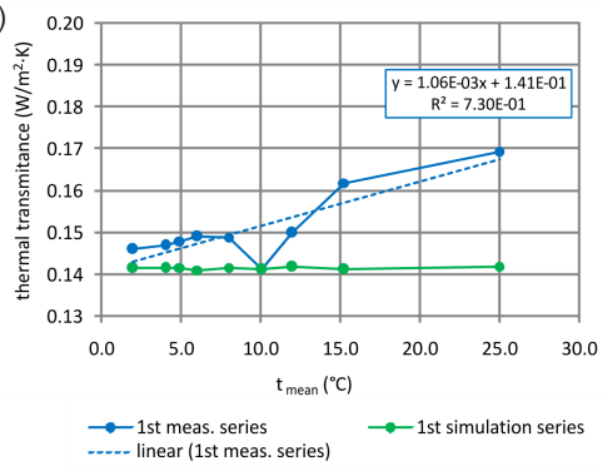

b)

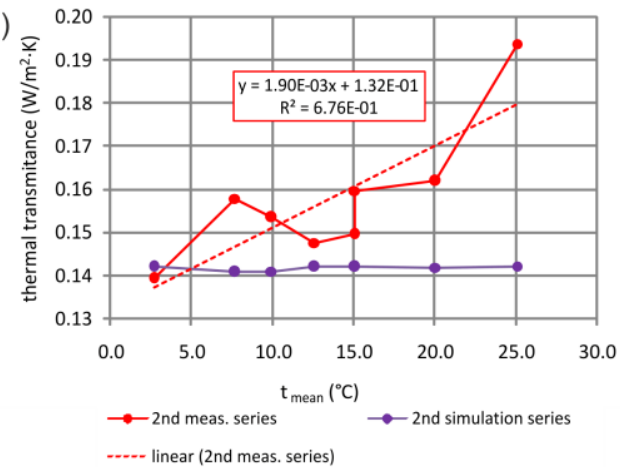

Fig. 4. Thermal transmittance results from the model and simulations for meas. series: a) $1^{\text {st }}$, b) $2^{\text {nd }}$.

\section{Conclusion}

The investigation carried out on a frame partition filled with loose wood wool prove the impact of the average temperature of the model on the thermal losses. Thermal resistance decreases with increasing temperature. This confirms the previous wood wool material tests. Two measuring series gave differing results, what is an important information for correct determination of thermal properties of models on a real scale. It is planned to continue the research on this model and compare the results with other loose materials.

\section{References}

1. M. Salonvaara, M. Pazera, A. Karagiozis, Impact of Weather on Predicting Drying Characteristics of Spray-Applied Cellulose Insulation (ASHRAE, 2010).

2. R. Wójcik, P. Kosiński, En. Proc. 78 (2015) 1519-1524.

3. D. Barnat-Hunek, P. Smarzewski, P. Brzyski, J of Nat. Fib. 14(3), 410-425 (2016)

4. M. A. Tarallo, Bio-Fibers and Their Use in Thermal Insulation Material (Syracuse University, New York, 2010).

5. S. Geving, E. Lunde, J. Holme, En. Proc. 78 ( 2015 ) 1455 - 1460.

6. A. Miros, A. Bajorek, J. Kubacki, Proceedings of the International Conference on Heat Transfer and Fluid Flow, paper no. 188, Prague (2014).

7. O. Vololonirina, M. Coutand, B. Perrin, Con. and Build. Mat. 63 (2014) 223-233

8. N. Bénichou, M.A. Sultan, C. MacCallum, J Hum, Thermal properties of wood, gypsum and insulation at elevated temperatures (Institute for Research in Construction National Research Council of Canada, 2001)

9. M. Orosz, B. Nagy, E. Tóth, Poll. Per. 12(2) 53-66 (2017)

10. F. N. Arumi, Thermal inertia in architectural walls (Herndon, VA: National Concrete Masonry Association, 1977)

11. S. J. Byrne, R. L. Ritschard, Proceedings of the ASHRAE/DOE/BTECC Conference on Thermal Performance of the Exterior Envelopes of Buildings III, Clearwater Beach, FL, 1225-1240 (1985).

12. Steico. Product information. Available at: www.steico.com (accessed 1 Feb. 2019). 